IP Periodica Polytechnica Electrical Engineering and Computer Science

59(3), pp. 125-131, 2015

DOI: $10.3311 /$ PPee. 8583

Creative Commons Attribution (i)

\section{Analysis of the Green Power Transition on Optimal Power Transformer Designs}

\author{
Tamás Orosz ${ }^{1}$, Péter Sőrés ${ }^{1 *}$, Dávid Raisz ${ }^{1}$, Ádám Z. Tamus ${ }^{1}$
}

Received 21 July 2015; accepted after revision 21 August 2015

\begin{abstract}
The main intent of the power transformer design optimization in the tendering stage is to find those mechanical and electrical parameters, which minimize the machines' total cost of the ownership by reducing the different power losses and the manufacturing costs. To find the optimal transformer design parameters and make them harmonize with the economic constraints is a labour intensive task, because these quantities are linked with complex trade-off and physical functions. The capitalization of the load and no-load losses facilitate this process. The focus of this paper is to examine the sensitivity of the design parameters from the capitalization factors. Three different scenarios are presented and analysed in this paper, where the transformers are connected to various stochastic or schedulable green power generation resources. This paper presents the optimal transformer design's dependency from the various scenarios of different green power generation resources.
\end{abstract}

\section{Keywords}

Geometric programming, lifetime cost optimization, power transformer, renewable energy sources

\footnotetext{
${ }^{1}$ Department of Electric Power Engineering,

Budapest University of Techology and Economics

H-1521 Budapest, P.O.B. 91, Hungary

*Corresponding author, e-mail: sores.peter@vet.bme.hu
}

\section{Introduction}

In the current market conditions, network operators, industrial consumers and power plant capacity installers are pressed to reduce the total real running costs of their equipment. Therefore the transformer manufacturing industry is continuously targeting to further reduce costs and improve the efficiency of their products, which ongoing progress have become the key to survival in a global market. They have to satisfy not only the high quality technical standards and specifications for noise reduction but the additional requirements to meet global and national commitments such as managing emissions of greenhouse gases in conformance with various protocols, as well.

The capitalization of the load and no-load losses is an effective method to take into consideration the lifetime operating costs of an asset. The calculation of these factors are based on not only the technological parameters, but on the financial conditions as well. The optimal design parameters of an electrical machine, are highly influenced by the capital recovery factor of the investment. [1-3]

The power transformer design optimization is a complex task, because an electric machine may be visualized as the site of several superimposed fields, namely an electric field, magnetic field, field of mechanical forces, field of conductive heat etc. [4] Moreover, to find not only a technologically correct but economical design, the transformer designer has to harmonize these contradictory physical constraints with the economic conditions simultaneously. These economic constraints are the following: cost of the power losses, manufacturing, transportation and operating costs. The optimal investment shall deliver a solution with the minimum long-term total cost of ownership to the transformer holder. Therefore the design of the electrical distribution machinery and the selection of equipment are becoming even more complex, as multiple criteria have to be evaluated. The widely used capitalization technique is made it possible to handle the designing process with an exact mathematical method to find the most economical power transformer offer. The calculation method of these capitalization factors is although thoroughly described in the current academic literature, mostly in the case of distribution transformers 
(e.g. [1], [2]). All of these papers - known by the authors - are describing a method, which tested on usually only a few possibilities of pre-manufactured design offers. In this paper the authors are presenting a novel approach to fully optimize the defining parameters of the active part of the power transformers based on the calculated capitalization factors.

The design term, in its broadest sense, means that it's entails the translation of specifications into information which describes the apparatus in the necessary detail and performance [4]. A simplified analytical model is sufficient to use in the investigated tender design case. In this research, a new meta-heuristic solution based transformer optimization method is used to calculate the optimal transformer parameters. The applied optimization method combines the geometric programming with the method of branch and bound to solve this nonlinear optimization problem. The application used for this calculation was specially developed for this research task.

The remainder of the paper is structured as follows. Chapter 2 briefly details the calculation of the transformers' total operation cost by determining the loss capitalization factors. Chapter 3 demonstrates the applied design optimization algorithm that seeks a minimum capitalized cost solution by setting the transformer's geometric and electric parameters to the optimum. The software uses geometric programming optimization which formalism guarantees that the global optimum point is determined by an efficient and reliable computing process [5], [6], [7]. In the next section, the effects of multiple scenarios regarding the financial cost of losses are examined. Different transformer designs are presented, each being the optimal choice for a given set of capitalization factors. The contribution of this method is that the different investment options can be compared more thoroughly with the theoretically optimal transformer design. Chapter 5 summarizes the paper and provides suggestions for further research.

\section{Capitalization Factors}

\subsection{Loss valuation by capitalization}

For a sound investment decision regarding a power transformer the applied methodology should include a thorough enumeration of losses along with the detailed upfront investment expenses. That is because the total cost of energy consumed by the operation of the transformer can range up to five times the initial cost of equipment. Thus the total life cycle cost of the transformer has to be evaluated including a loss estimation and the capitalization of future expenses to present price level to have a solid basis of investment decision for accurately compare different transformer offers, designs. The capitalization factors are calculated by adding the discounted cost of energy losses throughout the lifetime of the equipment to the direct purchase price $(P P)$. Installation and maintenance cost can be omitted, if essentially similar designs are compared (e.g. same cooling method). However (as we can see in Chapter 4) other characteristics of the final optimal transformer design generally differ by a quite a substantial factor. This distinct operating cost structure can be assessed by the calculation of no-load and load cost factors. Actual properties of operation, mostly the load factor of utilization plays a significant role on the amount of losses in a given transformer. Therefore a separated calculation of no-load loss $\left(\mathrm{P}_{\mathrm{NLL}}\right)$ and load loss $\left(\mathrm{P}_{\mathrm{LL}}\right)$ is reasonable, so the total cost of ownership (TCO) is expressed as [6]:

$$
T C O=P P+K_{1} \cdot P_{n l l}+K_{2} \cdot P_{l l}
$$

where $K_{1}$ and $K_{2}$ are the capitalization factors of no-load and load loss, respectively, in $[€ / \mathrm{kW}]$ dimension. The value of these factors are not only setting the absolute value of $K_{1}$ and $K_{2}$ for various transformer designs but the $K_{1} / K_{2}$ ratio is also a crucial input parameter for the design optimization. Nevertheless the hereby presented approach for the calculation of total cost only aims to give a proper method to compare different equipment, but not to result a full budgeting plan for the investment financing.

\subsection{Calculation of the Loss Capitalization Factors}

The most important variable regarding the life-time cost assessment is the discount rate $(r)$. The applicable number for this can be set by the finance cost (weighted average cost of capital) or by the recognized rate or return for a regulated entity. The accounting analogue of the expected operation lifetime of the equipment, the book-life $(T)$ dictates the time horizon of the analysis of future operational cost. The capital recovery factor $(C R F)$ shows the sum of the future expenses in annual payments of present-day currency. This factor can be deduced from principles regarding compounding interest, as follows:

$$
C R F=\frac{1-(1+r)^{-T}}{r}
$$

Energy cost $(E C)$ gives the conversion rate between the physical and the financial losses of the operation. The transformer losses also have to be delivered to the connection point. The cost of this additionally needed grid capacity is represented by an annualized charge per $\mathrm{kW}$ of maximum demand (IC). The IEEE standard for capitalization calculation can be fitted for distribution transformers [8]. However, with the modification of these equations regarding the demand and loading factors a suitable calculation can be obtained for the various load profiles of connecting transformers for distinct dispatchable and intermittent primary energy based resources. Demand factor is assumed to be 1, i.e. the nominal rating of the connecting transformer equals to the peak output of the various generating units. Instead of using approximating formula specified in load-loss factor $(L L F)$ can be obtained directly from the representative load profile curve:

$$
L L F^{2}=\frac{1}{T} \int_{T}^{\infty}\left(\frac{p(t)}{\max p(t)}\right)^{2} d t
$$


The capitalization factors are the results of the loss cost evaluation which sum of two terms. The first one is the annualized cost of maintaining the additional grid capacity, which is required to deliver the loss power. The second one is the cost of the energy lost (both to core and copper losses). No-load losses are always occurring on an energized transformer, mainly due to the hysteresis and eddy losses. Equation (3) details the calculation of the capitalized no-load losses (in $€ / \mathrm{kW}$ ):

$$
K_{1}=C R F \cdot(I C+8.76 h \cdot E C)
$$

The formula for capitalized load-loss cost has a very similar form, but the effect of the variable utilization shall be considered:

$$
K_{2}=C R F \cdot(I C+L L F \cdot 8.76 h \cdot E C)
$$

The load profile essentially determine $K_{1} / K_{2}$ ratio which will be the basic input data for the transformer design optimization. Therefore for the different intermittent and base load energy sources a diverse set of transformers proves to be optimal. Nevertheless, the contribution of $L L F$ is weighted by $E C$ in the final magnitude of $K_{2}$. So neither the cost of required electricity $(E C)$ nor the cost of power $(I C)$ can be neglected (the dimensions for these parameters are $€ / \mathrm{MWh}$ and $€ / \mathrm{kW} / \mathrm{a}$, respectively).

\subsection{Details of the Analysed Scenarios}

The usually investigated range of the annual discount rate is about 5 to $10 \%$ p.a. In our series of analysis we have calculated with $r=8 \%$, as in, while the lifetime basis $(T)$ used in depreciation is 25 years. The calculation focuses on the cost of losses for a medium to high voltage transformer connection of renewable power plants. Capacity cost of delivering the power losses to the transformer is estimated by the large consumers' payment to procure peak capacity from the distribution system operator. In Hungary, this tariff is fixed to about $5 € / \mathrm{kW} / \mathrm{a}$ for a high voltage point of common coupling [9].

The energy cost is uniformly charged for all consumed electricity, so this holds to the losses of the power transformer, as well. Therefore the $E C$ equals to the all-in cost of energy for this type of system users. This includes wholesale electricity and the energy-based transmission tariffs. In the Central and South Eastern European (CSEE) region altogether it is cca. 75€/MWh [10].

Finally, regarding the parameters of the load profile fullyear statistics are used for the renewable electricity sources. Load loss parameters for wind turbines, the load factor ( $L F$ $=0.24)$ and the load-loss factor $(L L F=0.12)$ is derived from total wind power time series as the idiosynchoricity of its individual generators are more than 0.95. [11] Similar holds for the photovoltaic power in-feed in Amprion's area $(L F=0.15$, $L L F=0.07)$. Using this aggregated measure of generation profiles still appreciates the utilization of a connection transformer of a single renewable power plant. [12] As biomass based generation can be scheduled, the analysis considered an average maintenance outage from the year-on constant base production with $L F=0.9$ and $L L F=0.88$. The resulting $K_{1}$ no-load loss capitalization factor is $7066 € / \mathrm{kW}$ for all generation types. $K_{2}$ factors are $925 € / \mathrm{kW}, 565 € / \mathrm{kW}, 6230 € / \mathrm{kW}$ for wind, $\mathrm{PV}$ and biomass based resources, respectively.

\section{The Transformer Design Optimization Method}

A geometric programming based optimization method is used for the determination of the cost optimal transformer. This optimization model is calculates with reduced details of data, which is enough for a tender design. This model takes into consideration only the transformers' active part, which consists of the winding and the iron core. The other parts (the tank, the quality of the insulating oil, the structural components and other accessories) are not calculated exactly in the tender design stage, the optimization method takes into consideration these factors by empirical constants. This method is also applied to the height of primary and regulation windings.

The resulting offer design needs to satisfy the other requirements required by the applied standards (i.e. IEC-60076 series, GOST, IEEE), technical specifications and by the customers' need, as well.

\subsection{The Geometric Programming Approach with the Method of Branch and Bound}

The applied optimization method is based on the Geometric Programming $(G P)$ formalism. The usage of this method has several advantages: guarantees that the obtained solution is the global minimum, solved efficiently by the novel solution algorithms. The $G P$ is a branch of the non-linear optimization problems given in the following form [13-16]:

$$
\begin{array}{r}
\operatorname{minimize}\left\{f_{0}\right\} \quad \text { subject to : } \\
f_{i}(x) \leq 1, \quad i=1, \ldots, m, \\
g_{j}(x)=1, \quad j=1, \ldots, o,
\end{array}
$$

where $\mathrm{x}=\left(\mathrm{x}_{1}, \mathrm{x}_{2}, \ldots \mathrm{x}_{\mathrm{n}}\right)$ is a vector containing the optimization variables, $f_{i}(x)$ is a posynomial constraint inequality, $g_{j}(x)$ is a monomial constraint equality function. All elements of $x$ must be positive. The monomial function $\mathrm{g}(\mathrm{x})$ expressed as:

$$
g(x)=c_{g} \cdot x_{1}^{\alpha_{1}} \cdot x_{2}^{\alpha_{2}} \ldots \cdot x_{n}^{\alpha_{n}}
$$

where $c_{\mathrm{g}} \in \mathfrak{R}, \alpha_{\mathrm{i}} \in \mathfrak{R}$ and $c_{g}>0$.

A posynomial is a linear combination of monomials:

$$
f(x)=\sum_{k=1}^{K} c_{k} \cdot x_{1}^{\alpha_{1 \mathrm{k}}} \cdot x_{2}^{\alpha_{2 \mathrm{k}}} \ldots x_{n}^{\alpha_{n k}} \text {. }
$$

In the case of power transformers the short-circuit impedance is an essential design parameter, but in case of the coreform transformers it cannot be formulated in the above shown monomial or posynomial form. To solve this problem the solution algorithm is mixing the method of GP with the method of branch and bound (B\&B). [17] 
The (B\&B) algorithm is a general method of finding optimal solutions for a large set of problems (detailed description can be found in [13]). Although it is often categorized as a metaheuristic, it can provide an optimality criterion as well as other quite advantageous features such as manageable solution pools and flexible tuning. B\&Bs main application area lies in the field of discrete and combinatorial programming, but its use is far from exclusive [14].

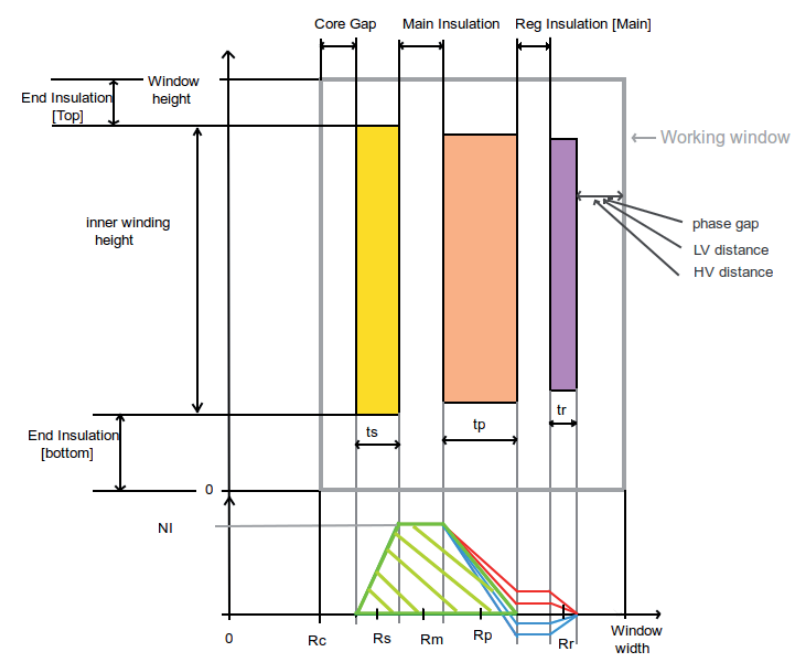

Fig. 1 Schematic view of the leakage field calculations and the design variables in the transformer's working window.

\subsection{The Geometric Programming Approach with the Method of Branch and Bound}

In the optimization model we take into consideration the active part of the transformer, because its dimensions determines the total cost of the equipment (Table 1). This original active part model extended with the dimensions of the transformer tank which is already capable to take into consideration the limitations of the outer dimensions and the mass of the tank. The active part model contains three windings: the realized transformer model in Fig. 1. In the example transformer, the high voltage winding regulated with an on-load tap changer. [18]

The objective function of the transformer $\left(\mathrm{f}_{0}\right)$ model is the previously showed capitalized cost of the transformer, which involves the manufacturing cost and the cost of the calculated losses,

$$
f_{0}=K_{1} \cdot P_{n l l}+K_{2} \cdot P_{l l}+\sum_{k=0}^{n} C_{k} \cdot M_{k} .
$$

where $\mathrm{C}_{\mathrm{k}}$ is the specific cost of the $\mathrm{k}^{\text {th }}$ material of the transformers' active part in $€ / \mathrm{kg}$ and $\mathrm{M}_{\mathrm{k}}$ is the mass of the $\mathrm{k}^{\text {th }}$ material in $\mathrm{kg}$. The manufacturing cost of the core is calculated simply as the product of the core mass and the unit price of the applied electrical steel. The core weight calculated from the built-in three legged, three phase transformer core model (Fig. 2) which geometry is expressed by the model variables. The Epstein-curve of the core material can be approximated with a posynomial function,
Table 1 Set of design variables in the optimization model

\begin{tabular}{|c|c|c|c|}
\hline \multicolumn{2}{|l|}{ Quantity } & Dimension & Variable \\
\hline \multicolumn{2}{|l|}{ Load loss } & {$[\mathrm{kW}]$} & $\mathrm{P}_{11}$ \\
\hline \multicolumn{2}{|l|}{ No-load loss } & {$[\mathrm{kW}]$} & $P_{n l l}$ \\
\hline \multicolumn{2}{|c|}{ Main insulation distance } & {$[\mathrm{mm}]$} & $\mathrm{g}$ \\
\hline \multicolumn{2}{|c|}{ Width of the working window } & {$[\mathrm{mm}]$} & $s$ \\
\hline \multicolumn{2}{|l|}{ Core induction } & {$[\mathrm{T}]$} & $B$ \\
\hline \multicolumn{2}{|l|}{ Core mass } & {$[\mathrm{kg}]$} & $M_{C}$ \\
\hline \multicolumn{2}{|l|}{ Tank length } & {$[\mathrm{mm}]$} & $A$ \\
\hline \multicolumn{2}{|l|}{ Tank width } & {$[\mathrm{mm}]$} & $B$ \\
\hline \multicolumn{2}{|l|}{ Tank height } & {$[\mathrm{mm}]$} & $\mathrm{C}$ \\
\hline \multirow{3}{*}{ Winding thickness } & secondary & {$[\mathrm{mm}]$} & $t_{s}$ \\
\hline & primary & {$[\mathrm{mm}]$} & $t_{p}$ \\
\hline & regulating & {$[\mathrm{mm}]$} & $\mathrm{t}_{\mathrm{r}}$ \\
\hline \multirow[t]{2}{*}{ Winding height } & secondary & {$[\mathrm{mm}]$} & $\mathrm{h}_{\mathrm{s}}$ \\
\hline & secondary & {$\left[\mathrm{A} / \mathrm{mm}^{2}\right]$} & $j_{s}$ \\
\hline \multirow[t]{2}{*}{ Current density } & primary & {$\left[\mathrm{A} / \mathrm{mm}^{2}\right]$} & $j_{p}$ \\
\hline & regulating & {$\left[\mathrm{A} / \mathrm{mm}^{2}\right]$} & $\mathrm{j}_{\mathrm{r}}$ \\
\hline \multirow{3}{*}{ Mean radius } & secondary & {$[\mathrm{mm}]$} & $\mathrm{R}_{\mathrm{s}}$ \\
\hline & primary & {$[\mathrm{mm}]$} & $R_{p}$ \\
\hline & regulating & {$[\mathrm{mm}]$} & $\mathrm{R}_{\mathrm{r}}$ \\
\hline
\end{tabular}

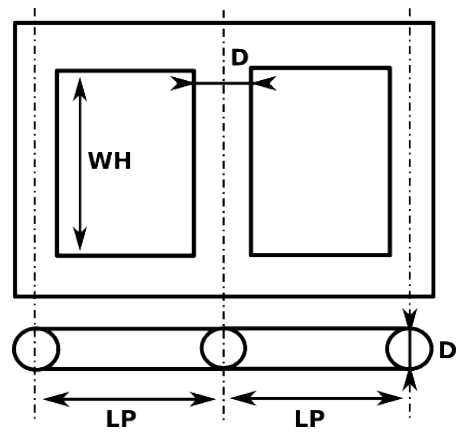

Fig. 2 Schematic view of the three phase three legged transformer core. "WH" means the window height, "LP" means the leg pitch and " $\mathrm{D}$ " is the leg diameter.

so the no-load loss of the transformer can be calculated very accurately with the product of the specific electrical steel loss, the core mass, and a technology specific building factor.

The mass of the windings is calculated from the winding geometry, with the copper filling factor. This factor is estimated with reasonable precision, from the manufacturer's database. The value of this filling factor is depends on the voltage level, the power and the type of the winding. It simplifies the winding model, because it can takes into consideration the different winding types with reasonable precision.

From the windings' copper mass, the DC losses are easily calculated. The precise calculation of stray losses needs 
advanced numerical or analytical methods. $[17,19,20]$ In the optimization algorithm an analytical formula is used to estimate the optimal eddy losses in the windings, and an empirical factor is used to take into consideration the other stray losses, which is generated in the structural components.

The transformer tank dimensions calculated from the outer dimensions of the active part and the insulating parameters. Limiting the outer dimensions has high importance, because the cost increment of the transportation are non-linear regarding the growing outer dimensions (e.g. structure gauge and mass limit of conventional road or railway shipping). The financial burden of the logistics can quickly outgrow what we have won by the softer limitations.

\section{Results and Discussion}

\subsection{General aspects of the transformer selection}

A 40 MVA power transformer is selected for the analysis. The datasheet of the power transformer is presented in Table 2, the transformer layout is in accordance to the previously presented optimization model and IEC-60076 standard. We assumed that the transformer is ONAN (oil natural, air natural) cooled, so we set the upper limit of the winding current density to $3 \mathrm{~A} / \mathrm{mm}^{2}$ because of cooling considerations.

The insulation distances selection based on the BIL and AC voltage test prescription, according the presented methods in $[17,19]$ and [20]. The low voltage winding is assumed as a layer type winding, built-from CTC cable, to reduce the eddy current losses and maximize the copper filling factor in the winding. The high voltage winding is assumed as a disc winding, built from radial twin or radial triple and twin conductors. We prescribed a minimal thickness, $10 \mathrm{~mm}$ for the regulating winding to increase the mechanical stability of this winding. The maximum flux density in the leg and the yokes are limited considering the transformer noise and the allowed maximum over-voltages.

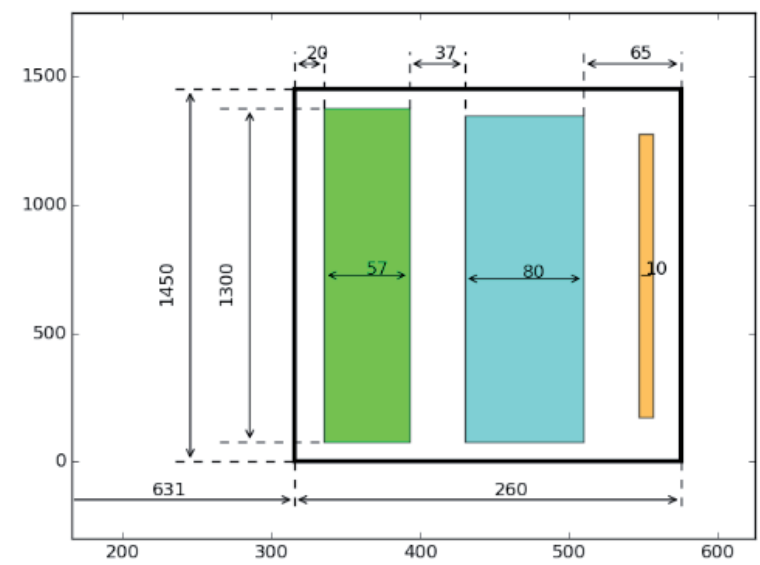

Fig. 3 Schematic view of the optimized transformer working window in the case of wind power generation.
Table 2 Datasheet and the Assumed Winding Types/Filling Factors of the Optimized Transformer

\begin{tabular}{|c|c|c|c|}
\hline \multicolumn{2}{|l|}{ Parameter } & Dimension & Value \\
\hline \multicolumn{2}{|c|}{ Nominal power } & [MVA] & 40 \\
\hline \multicolumn{2}{|l|}{ Frequency } & {$[\mathrm{Hz}]$} & 50 \\
\hline \multicolumn{2}{|c|}{ Connection group } & {$[-]$} & YNd11 \\
\hline \multicolumn{2}{|l|}{ Phase nr. } & {$[\#]$} & 3 \\
\hline \multicolumn{2}{|c|}{ Core-secondary insulation distance } & {$[\mathrm{mm}]$} & 20 \\
\hline \multicolumn{2}{|l|}{ Main gap } & {$[\mathrm{mm}]$} & 37 \\
\hline \multicolumn{2}{|c|}{ End insulation } & {$[\mathrm{mm}]$} & 180 \\
\hline \multicolumn{2}{|c|}{ Phase distance } & {$[\mathrm{mm}]$} & 37 \\
\hline \multicolumn{2}{|c|}{ OLTC diameter } & {$[\mathrm{mm}]$} & 530 \\
\hline \multicolumn{2}{|c|}{ Short-circuit impedance } & {$[\%]$} & 12 \\
\hline \multirow{5}{*}{ Core } & Nr. of legs & {$[\#]$} & 3 \\
\hline & $\mathrm{B}_{\max }$ & {$[\mathrm{T}]$} & 1.7 \\
\hline & Filling factor & {$[\%]$} & 90 \\
\hline & Material tyoe & {$[-]$} & $\mathrm{M} 1 \mathrm{H}$ \\
\hline & Material price & {$[€ / \mathrm{kg}]$} & 3.5 \\
\hline \multirow{4}{*}{$\begin{array}{l}\text { Secondary } \\
\text { Winding }\end{array}$} & Line voltage & {$[\mathrm{kV}]$} & 33 \\
\hline & Filling factor & {$[\%]$} & 70 \\
\hline & Winding/material type & {$[-]$} & helical/CTC \\
\hline & Insulated material price & {$[€ / \mathrm{kg}]$} & 8 \\
\hline \multirow{6}{*}{$\begin{array}{l}\text { Primary } \\
\text { Winding }\end{array}$} & Line voltage & {$[\mathrm{kV}]$} & 120 \\
\hline & $\mathrm{BIL}$ & {$[\mathrm{kV}]$} & 550 \\
\hline & $\mathrm{AC}$ & {$[\mathrm{kV}]$} & 230 \\
\hline & Filling factor & {$[\%]$} & 65 \\
\hline & Winding/material type & {$[-]$} & disc/twin \\
\hline & Insulated material price & {$[€ / \mathrm{kg}]$} & 7 \\
\hline \multirow{4}{*}{$\begin{array}{l}\text { Regulation } \\
\text { Winding }\end{array}$} & Type & {$[-]$} & $\begin{array}{l}\text { de-energized } \\
\text { OLTC }\end{array}$ \\
\hline & Filling factor & {$[\%]$} & 40 \\
\hline & Winding/material type & {$[-]$} & $\begin{array}{l}\text { multi-start/single } \\
\text { conductor }\end{array}$ \\
\hline & Insulated material price & {$[€ / \mathrm{kg}]$} & 8 \\
\hline
\end{tabular}

\subsection{Result of the Optimization}

The results are shown in the Table 3, that for all considered scenarios the cost of no-load losses are substantially high, therefore the optimal flux density is only $1.4 \mathrm{~T}$. That is essentially means the transformer has a huge iron core with low flux density which reduces the transformer noise. Figure 3 illustrates the optimal working window for the wind scenario. Also, the turn voltage is high in the given designs. Since the utilization factors are different in the three scenarios the cost and the optimal 
design of the transformers also varies. The results are shown that in case of photovoltaic and wind power generation in a regular investment environment the optimal transformer design has small no-load losses and high load losses. In contrary, a biomass type generating resource requires a more expensive equipment that has a relatively low load losses. Therefore the optimal configuration for this green energy source has a larger size and a substantially heavier iron core, about almost twice as the 22 tons for PV and wind power plants.

\section{Conclusion}

In this paper the calculation of transformer loss capitalization is presented and used for choosing the optimal transformer design. A geometric programming based optimization method is shortly presented in this article which is applied to compare the effect of the $K_{1}, K_{2}$ parameters on the active part model. The ratio of these factors fundamentally determines the main parameters of the transformer's active part. In contrast of other published research on capitalization cost calculation which only takes into consideration such transformer designs which are already in series production, in this research the transformer designs are the outcome.

Moreover a geometric programming based optimization is shortly introduced that enables comparing different transformer design regarding the outer measurements and the copper and iron masses. Three scenarios regarding the green power generation are considered for the calculation of the optimal transformer offer. The presented photovoltaic, wind and biomass technologies have fundamentally different characteristics regarding the capitalization factors.

Because of the utilization factors are different in each cases the optimal transformer design also varies. The results showed that in the case of the photovoltaic and wind power generation in a regular investment environment the optimal transformer design has small no-load losses and high load losses. That is essentially means the transformer has a large iron core with low flux density which reduces the transformer noise. The copper amount in the windings are low, so the current densities are relatively high. In contrast of these scenarios the optimal design in the case of biomass power generation, which has an almost unitary utilization factor, the high efficiency of the transformer is the fundamental property of the final equipment, resulting in relatively large copper masses.

In the future the research will be extended to include the various cooling methods that can be applied in a transformer that essentially influence the final optimal configuration of the active part. With the inclusion of the cost of the transformer oil into the optimization model one can assess the use of biodegradable, alternative dielectric fluids that could be adequate in light of the novel environmental regulations.
Table 3 Calculation results of the active part for each green power generation scenarios with different $\mathrm{K}_{1} / \mathrm{K}_{2}$ ratios

\begin{tabular}{ccccc}
\hline & & Wind & PV & Biomass \\
\hline $\mathrm{K} 1$ & $€ / \mathrm{kW}$ & 7066 & 7066 & 7066 \\
\hline $\mathrm{K} 2$ & $€ / \mathrm{kW}$ & 926 & 565 & 6225 \\
\hline
\end{tabular}

Core

\begin{tabular}{llccr}
\hline Diameter & $\mathrm{mm}$ & 631 & 636 & 752 \\
\hline Flux density & $\mathrm{T}$ & 1.4 & 1.4 & 1.4 \\
\hline Mass & ton & 22.2 & 22 & 38.5 \\
\hline Turn Voltage & $\mathrm{V}$ & 89.6 & 89 & 126 \\
\hline
\end{tabular}

Secondary Winding

\begin{tabular}{llrrr}
\hline Mean diameter & $\mathrm{mm}$ & 671 & 676 & 792 \\
\hline Winding height & $\mathrm{mm}$ & 1300 & 1242 & 1460 \\
\hline Winding width & $\mathrm{mm}$ & 57 & 57 & 96 \\
\hline Turn number & $\#$ & 213 & 214 & 151 \\
\hline Current density & $\mathrm{A} / \mathrm{mm}^{2}$ & 3 & 3 & 1 \\
\hline
\end{tabular}

Primary Winding

\begin{tabular}{llrrr}
\hline Mean diameter & $\mathrm{mm}$ & 860 & 865 & 1101 \\
\hline Winding height & $\mathrm{mm}$ & 1274 & 1217 & 1431 \\
\hline Winding width & $\mathrm{mm}$ & 80 & 68 & 142 \\
\hline Turn number & $\#$ & 773 & 779 & 550 \\
\hline Current density & $\mathrm{A} / \mathrm{mm}^{2}$ & 2 & 3 & 1
\end{tabular}

Regulating

\begin{tabular}{llrrr}
\hline Mean diameter & $\mathrm{mm}$ & 1094 & 1076 & 1459 \\
\hline Winding height & $\mathrm{mm}$ & 1105 & 1056 & 1241 \\
\hline Winding width & $\mathrm{mm}$ & 10 & 10 & 10 \\
\hline Current density & $\mathrm{A} / \mathrm{mm}^{2}$ & 3 & 3 & 2 \\
\hline
\end{tabular}

Losses

\begin{tabular}{lcccc}
\hline Load loss & $\mathrm{kW}$ & 147.9 & 170 & 49.7 \\
\hline No-load loss & $\mathrm{kW}$ & 19.2 & 18 & 32.2
\end{tabular}

\begin{tabular}{llccc}
\hline Costs & & & & \\
\hline Copper & $\mathrm{k} €$ & 59.2 & 52.4 & 138.4 \\
\hline Core & $\mathrm{k} €$ & 66.6 & 66 & 115.5 \\
\hline Capitalization & $\mathrm{k} €$ & 272.6 & 223.2 & 536.9 \\
\hline TCO & $\mathrm{k} €$ & 398.4 & 341.6 & 790.8 \\
\hline
\end{tabular}

Also, the property of intermittency can be exploited in a more sophisticated way by allowing the frequent overloading of the connecting transformer. That is an already known design requirement in railway traction transformers, therefore the adaptation of these design types to the connection of variable PV and wind generation can easily prove to be a promising approach. 


\section{References}

[1] Georgilakis, P. S. "Environmental cost of distribution transformer losses." Applied Energy. 88 (9). pp. 3146-3155. 2011.

DOI: 10.1016/j.apenergy.2010.12.021

[2] Corhodzic, S., Kalam, A. "Assessment of distribution transformers using loss capitalization formulae." Journal of Electrical and Electronics Engineering Australia. 20 (1). pp. 43-48. 2000.

[3] Sores, P., Orosz, T., Vajda, I. "Lifetime cost sensitivity assessment on optimal core-form power transformer design." CRF. 11 (1). p. 2. 2014. DOI: $10.13140 / 2.1 .1161 .2169$

[4] Abetti, P. A., Cuthbertson, W. J., Williams, S. B. "Philosophy of applying digital computers to the design of electric apparatus." American Institute of Electrical Engineers, Part I: Communication and Electronics, Transactions of the. 77 (3). pp. 367-379. 1958. DOI: 10.1109/TCE.1958.6372814

[5] Boyd, S., Kim, S.-J., Vandenberghe, L., Hassibi, A. "A tutorial on geometric programming." Optimization and Engineering. 8 (1). pp. 67-127. 2007. DOI: 10.1007/s11081-007-9001-7

[6] Boyd, S., Vandenberghe, L. "Convex Optimization." Cambridge University Press, 2004.

[7] Orosz, T., Vajda, I. "Design optimization with geometric programming for core type large power transformers." Electrical, Control and Communication Engineering. 6 (1). pp. 13-18. 2014. DOI: 10.2478/ecce-2014-0012

[8] "IEEE Loss Evaluation Guide for Power Transformers and Reactors." In: IEEE Std C57.120-1991. 1992. DOI: 10.1109/IEEESTD.1992.114388

[9] "MEKH Hungarian Energy and Public Utility Regulatory Authority. System usage tariffs from 1st jan. 2015." 2015. [Online]. Available from: http://mekh.hu/download/f/d0/00000/rendszerhasznalati_dijtetelek_2015 januar.xlsx [Accessed: 01 April 2015].

[10] Nagy, Z. "Hungarian Chapter of International Federation of Industrial Energy Consumers (IFIEC). Power market situation for end-users in the cee, see and cis sub-regions in the end of 2013." 2013. [Online]. Available from: http://www.ief.hu/hu/villamos-tagozat/piaci-\%C3\%A1 rak [Accessed: 09 April 2015].
[11] "MAVIR TSO. Hungarian power system actual data: Wind production, 2015." [Online]. Available from: http://www.mavir.hu/web/mavir-en/ wind-production [Accessed: 03 May 2015].

[12] "Amprion TSO. Grid data - photovolatic infeed." 2015. [Online]. Available from: http://www.amprion.net/en/grid-data [Accessed: 10 May 2015].

[13] Achterberg, T. "Constraint Integer Programming." Ph.D. Thesis. Technische Universität Berlin. 2007. URL: http://opus.kobv.de/tuberlin/volltexte/2007/1611/

[14] Liberti, L. "Introduction to Global Optimization." 2008, [Online]. Available from: http://www.lix.polytechnique.fr/ liberti/teaching/globalopt-lima.pdf [Accessed: 13 January 2015]

[15] Andersen, M. S., Dahl, J., Vandenberghe, L. "Cvxopt: A python package for convex optimization." version 1.1. 6. Available at: cvxopt.org, 2013.

[16] Duffin, R. J., Peterson, E. L., Zener, C. "Geometric programming: theory and application." Wiley, New York, 1967.

[17] Del Vecchio, R. M., Poulin, B., Feghali, P. T., Shah, D. M., Ahuja, R. "Transformer design principles: with applications to core-form power transformers." CRC press, 2010.

[18] Jabr, R. A. "Application of geometric programming to transformer design. Magnetics." IEEE Transactions on Magnetics. 41 (11). pp. 42614269. 2005. DOI: 10.1109/TMAG.2005.856921

[19] Karsai, K., Kerenyi, D., Kiss, L. "Large power transformers." 1987.

[20] Kulkarni, S. V., Khaparde, S. A. "Transformer engineering: design and practice." Vol. 25. CRC Press, 2004. 